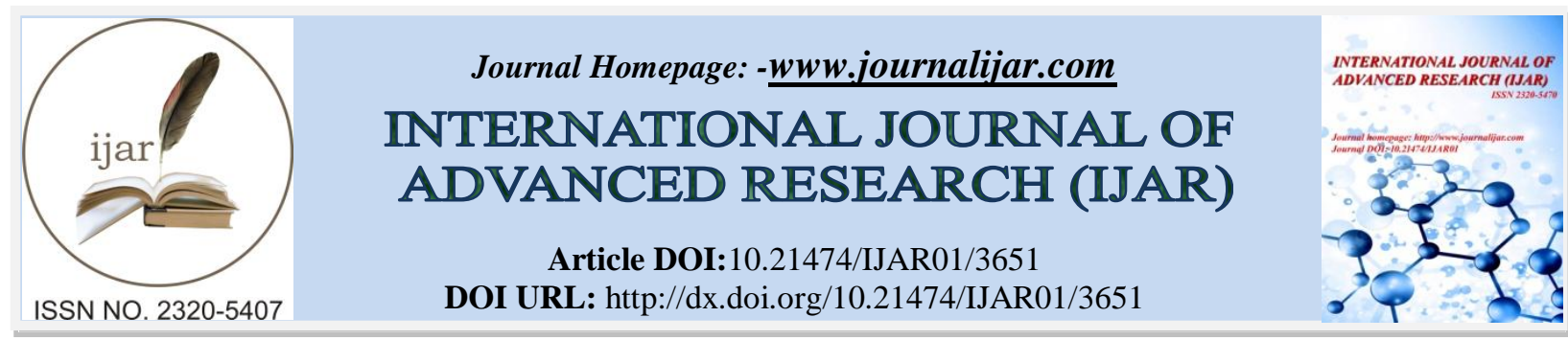

RESEARCH ARTICLE

\title{
RHEUMATOID ARTHRITIS SEVERITY INDEX AND ITS RELATION TO COMORBIDITY IN EGYPTIAN RHEUMATOID ARTHRITIS PATIENTS.
}

\author{
Samah M. Alian ${ }^{1}$, Rabab S. Zaghlol ${ }^{1}$, Sahar S. Khalil ${ }^{1}$, Dalia A. El-Shafei ${ }^{2}$, Samah S. Sheta ${ }^{2}$ and Marwa B. \\ Awad Allah ${ }^{3}$. \\ 1. Rheumatology and Rehabilitation Department, Faculty of Medicine, Zagazig University, Egypt. \\ 2. Department of Community, Environmental and Occupational Medicine, Faculty of Medicine, Zagazig \\ University, Egypt. \\ 3. Department of Public Health and Preventive Medicine, Faculty of Medicine, Zagazig University, Egypt.
}

\section{Manuscript Info}

Manuscript History

Received: 09 January 2017

Final Accepted: 10 February 2017

Published: March 2017

\section{Abstract}

Objective: This study aimed to apply the previously validated Rheumatoid arthritis medical records-based index of severity index (RARBIS) to RA patients in Egyptians and its relation to Comorbidity.

Method: Data of RA patients retrospectively collected from medical records in the follow up unit of the Rheumatology and Rehabilitation Department of Zagazig University hospital.The data were collected as regarding socio-demographic and clinical characteristics of the studied RA patients,the collected data were computerized and statistically analyzed using SPSS programversion 20.0

Results: A total of 1142 patients files were reviewed and included in the study, their ages ranged from (20-73) years and the duration of the RA disease ranged from (1-20) years.

We found that the total (RARBIS) score ranged from 3-16 with a mean of $8.09 \pm 2.41$. Also, the most frequent comorbidities in our patients are osteoporosis, hypertension, and peptic ulcer. RARBIS total score was high significant statistically increased in RA patients with comorbidities compared to those without comorbidities. In addition, the mean age of RA patients, rural area residency and illiteracy, increasing disease duration, prescribed NSAIDs or prednisolone were associated with high frequency increase in RA comorbidities. It was found that no significant difference when comparing frequency of comorbidities with sex, smoking and working status.

Conclusion: Our study demonstrated that the Egyptian RA patients have relatively high scores of severity index, and most of patients with severe RA suffer from a number of associated comorbidities withsignificant relationship with the severity index.

Copy Right, IJAR, 2017,. All rights reserved.

\section{Introduction:-}

Rheumatoid arthritis (RA) is the most common chronic inflammatory joint disease with the average prevalence of $0.5-1 \%$ in developed population ${ }^{1}$, and of $0.3-0.5 \%$ in developing countries ${ }^{2}$. This disease results in long-term disability and premature mortality in the patients $\mathbf{3}^{\mathbf{3}}$. 
Comorbid diseases are the medical conditions associated with RA. The mechanisms of this association may be due to the pathogenesis of RA itself, the effects of medications used for treating RA, or only a coincidence ${ }^{4}$. Substantial evidence indicates that the continuous systemic inflammation and immune dysfunction characteristic for RA plays a critical role in the development and acceleration of comorbidities ${ }^{5}$.

Comorbidities most frequently seen in patients with RA include cardiovascular disease, lung disease, malignancies, osteoporosis, changes in body composition and neuropsychiatric disease. Most of these comorbidities occur more frequently than expected in RA patients as compared to the general population. The average patient with RA has two or more comorbid disorder ${ }^{6}$.

RA disease severity is a major predictor of development of comorbidities. Surveys indicate that although clinical outcomes have improved in patients with RA, mainly due to access to more efficient pharmacotherapy, comorbidity remains a major issue in many patients. As a part of strategies to improve further the management of patients with RA, multidisciplinary collaboration for prevention and early detection of comorbidities is of major importance ${ }^{7}$. Because RA severity may affect both choice of treatment and incidence of comorbid conditions, RA severity is an important potential confounder in pharmacoepidemiologic studies.

The patient may have severe RA but been unable to take more potent therapy due to contraindications, including comorbid conditions ${ }^{9}$. As the comorbid conditions may impact treatment regimens of RA, or the prescribed drugs may worsen the comorbidity. Additionally, in many instances, rheumatologist may be forced to prescribe RA medications that exacerbate the comorbid conditions. Therefore, to successfully manage RA, comorbidities should be carefully considered and they should be treated in addition to prescribing anti-rheumatoid medication regimens. As RA patients with more comorbidities experience greater functional impairment ${ }^{\mathbf{1 0}}$. Rheumatoid arthritis medical records-based index of severity index (RARBIS) was developed through an expert Delphi panel of six rheumatologists, and convergent validity was assessed by comparing it with intensity of the actual RA treatments that patients received. The index includes indicators from five categories: prior surgical history $(\mathrm{C} 1-\mathrm{C} 2$ fusion and joint surgeries), radiologic findings ( $\mathrm{C} 1-\mathrm{C} 2$ subluxation and erosions), laboratory findings (rheumatoid factor (RF), erythrocyte sedimentation rate (ESR), C-reactive protein (CRP), and platelet counts), clinical and functional status (arthritis flares, morning stiffness, physician global rating, and functional status), and extra-articular manifestations (vasculitis and pulmonary nodule) ${ }^{8}$.

This study used a previously validated (RARBIS) for rheumatoid arthritis to estimate the distribution of disease severity and the association between disease severity and comorbidity in Egyptian RA patients from Sharkia Governorate, Egypt

\section{Methods:-}

\section{Subjects:-}

Data of RA retrospectively collected from medical records in the follow up unit of the Rheumatology and Rehabilitation Department of Zagazig University hospital (Monocentric study).The Zagazig University Hospitals is the biggest hospital in eastern Egypt that provides health care to the population in that part of Egypt, as it full of highly qualified professors and doctors of various specialties.

The data were collected as regarding socio-demographic and clinical characteristics of the studied RA patients, We obtained information on surgical history ( $\mathrm{C} 1-\mathrm{C} 2$ fusion and joint surgery), laboratory values (RF, ESR, CRP and platelet counts), extra-articular manifestations (subcutaneous nodules and vasculitis) and X-rays (C1-C2 subluxation, erosions), out-patient medications prescribed, comorbid conditions, and clinics attended were retrieved from the patients' physical file. Because the RARBIS does not require a physician's assessment for its calculation, it is easily applied retrospectively to medical records. All of the data for the RARBIS are accessible from medical records.

A total of 1142 patients files were reviewed, the diagnoses of RA based on the 1987 American College of Rheumatology criteria were included in the study, their ages ranged from (20-73) years and the duration of the RA disease ranged from (1-20) years. 


\section{Objective:-}

This study aimed to apply the previously validated severity index for rheumatoid arthritis (RARBIS score) to RA groups in Egyptians and its relation to Comorbidity.

\section{Statistical analysis:-}

The collected data were computerized and statistically analyzed using SPSS program (Statistical Package for Social Science) version 20.0. Qualitative data were represented as frequencies and percentages. Chi-square test (X2) was carried out for comparing the qualitative data. Quantitative data were compared using student's t-test. The test results were considered significant when $\mathrm{p}$-value $<0.05$ and highly significant when $\mathrm{p}$-value $<0.01$.

\section{Results:-}

A total of 1142 RA patients were included in the study. Most of them were females (79.6\%) with mean age of 43.86 \pm 11.40 . Only (14.6\%) of them were from urban areas and had higher education (15.1\%). Most of patients were nonworking $(82.3 \%)$ but only $(7.7 \%)$ were current smokers, with mean disease duration of about $9.24 \pm 4.76$. As regarding treatment, more than half of patients $(68.1 \%)$ were on non-steroidal anti-inflammatory drug NSAIDs, and $(87.1 \%)$ on prednisolone (Table 1).

Table (1): Socio-demographic and Characteristics data of the studied RA patients:

\begin{tabular}{|c|c|}
\hline Variables & $\begin{array}{c}\text { No. }(\%) \\
(\text { n. }=1142)\end{array}$ \\
\hline $\begin{array}{l}\text { Age }(\text { years) } \\
\text { Mean } \pm \text { SD } \\
\text { Range } \\
<50 \text { years } \\
\geq 50 \text { years }\end{array}$ & $\begin{array}{c}43.86 \pm \mathbf{1 1 . 4 0} \\
20-73 \\
402(35.2) \\
740(64.8)\end{array}$ \\
\hline $\begin{array}{l}\text { Gender } \\
\text { Female } \\
\text { Male }\end{array}$ & $\begin{array}{l}909(79.6) \\
233(20.4)\end{array}$ \\
\hline $\begin{array}{l}\text { Residence } \\
\text { Rural } \\
\text { Urban }\end{array}$ & $\begin{array}{l}975(85.4) \\
167(14.6)\end{array}$ \\
\hline $\begin{array}{l}\text { Level of education } \\
\text { Illiterate } \\
\text { Basic education } \\
\text { Higher education }\end{array}$ & $\begin{array}{l}735(64.4) \\
235(20.6) \\
172(15.1) \\
\end{array}$ \\
\hline Current Smokers & $88(7.7)$ \\
\hline $\begin{array}{l}\text { Working status } \\
\text { Non-working } \\
\text { Working }\end{array}$ & $\begin{array}{l}940(82.3) \\
202(17.7)\end{array}$ \\
\hline $\begin{array}{l}\text { Disease duration }(\text { years }) \\
\text { Mean } \pm \text { SD } \\
\text { Range } \\
<5 \text { years } \\
5-10 \text { years } \\
>10 \text { years } \\
\end{array}$ & $\begin{array}{c}9.24 \pm 4.76 \\
1-20 \\
179(15.7) \\
616(53.9) \\
347(30.4) \\
\end{array}$ \\
\hline $\begin{array}{l}\text { RA-related medications } \\
\text { NSAIDs } \\
\text { Prednisolone }\end{array}$ & $\begin{array}{l}778(68.1) \\
995(87.1)\end{array}$ \\
\hline
\end{tabular}

As regard to RARBIS of RA patients (Table 2), only 17 patients (1.5\%) had prior surgical histories, while 473 patients $(41.4 \%)$ had radiologic joint destructions. Extra-articular manifestations (vasculitis and pulmonary nodules) were evident in $61(5.4 \%)$ of RA patients, (RF) were positive in about half of them (53.3\%), where the other Laboratory sub-scale (Erythrocyte sedimentation rate > age/2 or C-reactive protein > upper limit normal or platelets $>450 \mathrm{~K}$ ) were observed in most RA patients $(87.5 \%)$. The optional RARBIS score with medication use was also calculated with the addition of data on medication use. As regarding treatment, more than half of patients were on 
DMARDS (Disease-modifying Anti-rheumatic Drugs).The Summary score for extended index was calculated by summing the five subscales ranged from 3-16 with a mean of $8.09 \pm 2.41$.

Table 2:- Rheumatoid arthritis medical records-based index of severity (RARBIS):

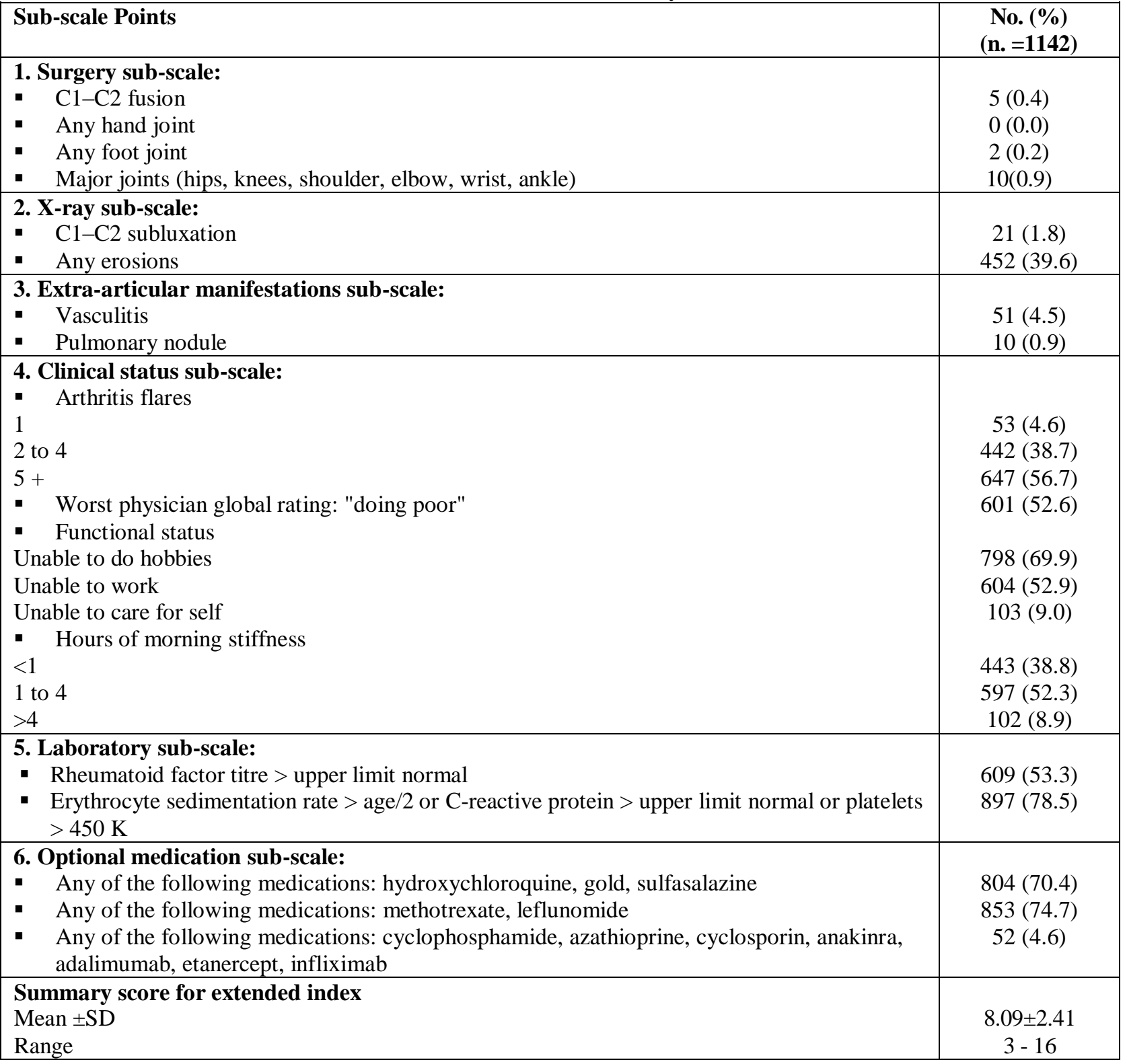

Graph (1) showed that the frequency of comorbidity among the studied RA patient was $(62.2 \%)$. Higher frequencies of comorbidities were noticed for osteoporosis $(39.1 \%)$, eye $(36.5 \%)$, hypertension $(32.2 \%)$ and peptic ulcer (27.2\%). (22.4\%) of studied RA patients had psychiatric problems (mostly depression), (20.1\%) were Diabetic and (17.6) had hepatitis viral infection. (15.1\%) of the patients had abnormal serum levels of lipids. While cancer, chronic renal disease, and coronary heart disease, represented lower frequencies (1.1\%, 2.6\%, 3.7\%; respectively). 
Graph 1:-Frequency of comorbidity among the studied RA patients

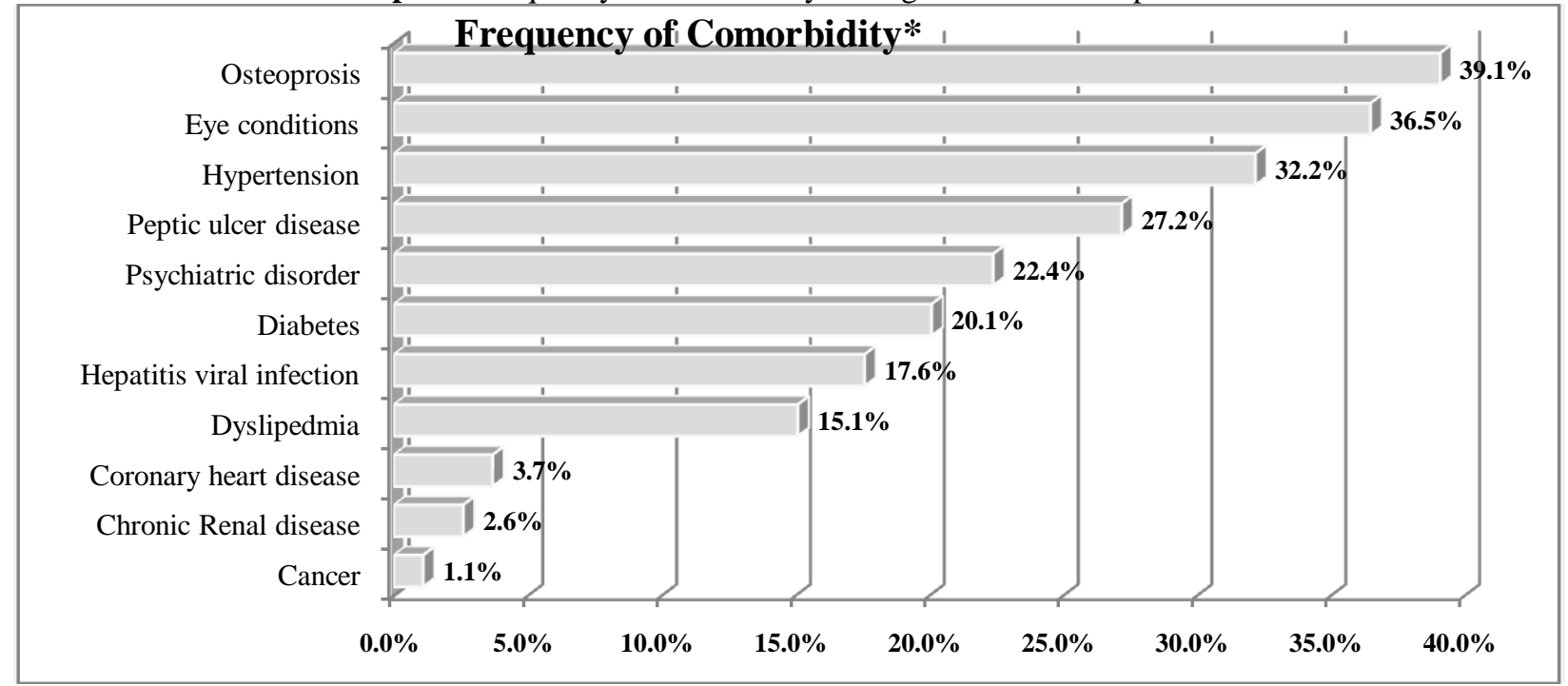

* Patients can be counted more than twice if they have more than one comorbid disease, therefore the total will not equal (the number of patients in the cohort)

Relationship between socio-demographic and characteristics data of the studied RA patients and comorbidity is demonstrated in Table 3.Mean age of RA patients with comorbidity was highly significantly older than RA patients without comorbidities $(p<0.000)$. Also, rural area residency and illiteracy $(p<0.000)$ were significant predictors of comorbidity among RA patients. There was a highly significant increase in the frequency comorbidity with increasing disease duration $(\mathrm{p}<0.000)$. As regarding treatment, patients with prescribed NSAIDs, or prednisolone showed significantly higher prevalent comorbidities $(\mathrm{p}<0.0001)$.

It was found that no significant difference when comparing frequency of comorbidities with sex, smoking and working status $(\mathrm{P}>0.05)$.

As regard RA severity index total score analyses, we found that RARBIS total score was high statistically increased inRA patients with comorbidities compared to those without comorbidities (Table 3).

Table 3:-Relationship between socio-demographic and severity index score of the studied RA patients and comorbidity:

\begin{tabular}{|c|c|c|c|c|}
\hline Variables & $\begin{array}{c}\text { RA patients with } \\
\text { comorbidity } \\
(n=710)\end{array}$ & $\begin{array}{l}\text { RA patients without } \\
\text { comorbidity } \\
(n=432)\end{array}$ & Test & $\mathbf{p}$ \\
\hline $\begin{array}{l}\text { Age }(\text { years }) \\
<50 \text { years } \\
\geq 50 \text { years } \\
\text { Mean } \pm \text { SD }\end{array}$ & $\begin{array}{c}187(26.3) \\
523(73.7) \\
54.33 \pm 8.77\end{array}$ & $\begin{array}{c}215(49.8) \\
217(50.2) \\
35.22 \pm 12.43\end{array}$ & $\begin{array}{r}64.6 \\
30.38\end{array}$ & $\begin{array}{l}0.000 * \\
0.000 *\end{array}$ \\
\hline $\begin{array}{l}\text { Gender } \\
\text { Female } \\
\text { Male }\end{array}$ & $\begin{array}{l}568(80.0) \\
142(20.0)\end{array}$ & $\begin{array}{c}341(78.9) \\
91(21.1)\end{array}$ & 0.19 & 0.665 \\
\hline $\begin{array}{l}\text { Residence } \\
\text { Rural } \\
\text { Urban }\end{array}$ & $\begin{array}{c}660(93.0) \\
50(7.0)\end{array}$ & $\begin{array}{l}315(72.9) \\
117(27.1)\end{array}$ & 86.4 & $0.000 *$ \\
\hline $\begin{array}{l}\text { Education } \\
\text { Illiterate } \\
\text { Literate }\end{array}$ & $\begin{array}{l}588(82.8) \\
122(17.2)\end{array}$ & $\begin{array}{l}147(34.0) \\
285(66.0)\end{array}$ & 279.0 & $0.000^{*}$ \\
\hline Current Smokers & $57(8.0)$ & $31(7.2)$ & 0.274 & 0.600 \\
\hline $\begin{array}{l}\text { Working status } \\
\text { Non-working }\end{array}$ & $588(82.8)$ & 352 (81.5) & 0.329 & 0.566 \\
\hline
\end{tabular}




\begin{tabular}{|l|c|c|c|c|}
\hline Working & $122(17.2)$ & $80(18.5)$ & & \\
\hline Disease duration (years): & & & & \\
$<5$ years & $22(3.1)$ & $157(36.3)$ & & \\
$\geq 5-<10$ years & $353(49.7)$ & $263(60.9)$ & 593.0 & $0.000^{*}$ \\
$\geq 10$ years & $342(48.2)$ & $7.54 \pm 2.37$ & 21.44 & $0.000^{*}$ \\
Mean \pm SD & $12.33 \pm 4.26$ & $188(43.5)$ & 194.0 & $0.000^{*}$ \\
\hline RA-related medications & $590(83.1)$ & $350(81.0)$ & 23.1 & $0.000^{*}$ \\
NSAIDs & $645(90.8)$ & & & \\
Prednisolone & & $5.79 \pm 2.38$ & 22.04 & $0.000^{*}$ \\
\hline RA severity index total score & $9.54 \pm 3.01$ & & \\
(RARBIS)
\end{tabular}

* Statistically highly significant.

\section{Discussion:-}

Our study demonstrated that the most patients with severe RA suffer from a number of associated comorbidities. These comorbid conditions may impact treatment regimens of RA, or the prescribed drugs may worsen the comorbidity. Therefore, to successfully manage RA, comorbidities should be carefully considered and they should be treated in addition to prescribing RA regimens medication.

Similar to previous studies likeIkuyamaet $\mathbf{a l}^{\mathbf{1 1}}$, our study showed that more women (79.6\%) than men (20.4\%) suffer from RA. Also, in our study, the average patient age was $43.86 \pm \mathbf{1 1 . 4}$ years, which is similar to the average age of patients with RA inSineglazova et al. study ${ }^{12}$.

Personal characteristics of Egyptian patients showed lower educational level and smoking status with common nonworking status, these findings are may be related to cultural and economic background ${ }^{13}$. Which would have as a consequence poor compliance to treatment, and therefore, poor control of the inflammatory activity of RA. In addition, biologic therapy is expensive and not covered or reimbursed governmentally or routinely by insurance. So, As regarding treatment, more than half of patients $(68.1 \%)$ were on NSAIDs, and $(87.1 \%)$ on prednisolone, which were comparable with that from a study on established RA study done by Osiri\&Sattayasomboon ${ }^{4}$.The rate of prednisolone used in our patients was $87.1 \%$, which was comparable with that from Briggs et al. study ${ }^{\mathbf{1 4}}$ and AlBishri et al. study ${ }^{15}$.

RA severity is considered complex measure determined by objective components such as disease activity (for example, tender/swollen joints and acute-phase reactants) and physical damage (for example, radiologic damage, and functional disability) and subjective components (for example, global health assessment, pain, grip strength, fatigue, and costs). The RARBIS does not require a new physician's assessment and the information on indicators can be routinely collected from typical medical records ${ }^{\mathbf{1 6}}$.

To the best of our knowledge, this is the first study discuss the RARBIS among Egyptian RA patients. We found that the total score ranged from 3-16 with a mean of 8.09 \pm 2.41 and this relatively consider high score, although our patients haven't large percent of extra articular manifestations like vasculitis $(4.5 \%)$ or pulmonary nodules $(0.9 \%)$ or cervical subluxation $(1.8 \%)$, but our patient have higher disease activity clinically and laboratory with more flares 2 4 (38.7\%), with 5 arthritis flare (56.7\%), high inflammatory markers as ESR and CRP (78.5\%) high RF (53.3\%), high DMARDs usage like; hydroxychloroquine, gold, sulfasalazine (70.4\%) \& methotrexate, leflunomide (74.7\%) and this uncontrolled disease may be due to educational and sociocultural aspects, which would have as a consequence poor compliance to treatment, and therefore, poor control of the inflammatory activity of RA, as well as a lower use of biological agents; drugs that show an important ability to induce remission in RA; due to the economic problems in our country.

We studied also the comorbid conditions associated with our RA patients and found that $62.2 \%$ patients had at least one comorbidity. These results were consistent with several results where study done by Al-Bishriet al. ${ }^{15}$ found that (66.0\%) patients of the 340 investigated were found to suffer from at least one comorbidity. In addition, Osiri\&Sattayasomboon ${ }^{4}$ study revealed that theprevalence comorbidities in RA patients ranged from 54.0 to $56.8 \%$. The higher frequencies of comorbidities were noticed for osteoporosis $(39.1 \%)$ which is similar to the study 
done byBriggset al. study ${ }^{14}$ which revealed that the frequency of osteoporosis in the studied RA was (31.0\%) and this match can reflect that the use of steroid is a major factor in susceptibility to osteoporosis in some RA patients.

As regarding eye problems frequencies (36.5\%), our study was in agreement with the study done by Osiri\&Sattayasomboon ${ }^{4}$, they found that the frequency of eye conditions (34.6\%) (KCS, cataract, glaucoma).

Also, our results matched with the study done by Al-Bishriet al. ${ }^{15}$ among Saudi RA patients, we found that (36\%) of RA patients had hypertension in comparison of the studied RA (32.2\%). Further, it seems that Egyptian patients had also highest ever prevalence of gastric ulcers $(27.2 \%)$ which is similar to El-Zorkany et al ${ }^{\mathbf{1 3}}$ which revealed the prevalence of gastric ulcer (22.0\%) as compared to prevalence in all other participating countries (10.0\%). So, the management strategy which concentrates on the use of available NSAIDs, steroids, and synthetic DMARDs would be responsible ${ }^{17}$.

We found $(22.4 \%)$ of studied RA patients had psychiatric problems mainly depression, this finding consistent with previous studies in a cohort study of more than 33000 patients with RA, depressive symptoms were reported by $11.7 \%$ of patients. There was association RA and depression and the coexistence of depression and RA is associated with increased pain, fatigue, reduced health-related quality of life, increased physical disability and healthcare $\operatorname{costs}^{18}$.And also matched the meta-analysis that included 13.189 patients with RA from 72 studies, the prevalence of a major depressive disorder was found to be $16.8 \%{ }^{19}$.

In this study we observed that the frequency of diabetes mellitus was (20.1\%) which were in agreement with the study done by Espiño-Lorenzo et al. ${ }^{20}$ and revealed that (27.0\%) of RA patients were diabetic.

Our results not matched with the study done by El-Zorkany et $\mathbf{a l}^{\mathbf{1 3}}$ which was done on 308 Egyptian patients with RA and found that RA with hepatitis viral infection were (7.1\%) but in our study (17.6\%) had hepatitis viral infection and these differences may be related to different sample size, and residency and sociocultural aspect.

We observed (15.1\%) of theRA patients had abnormal serum levels of lipids and this finding consistent with previous study done by Al-Bishri et al. ${ }^{\mathbf{1 5}}$ who found that (19.4\%) of RA patients had dyslipidemia.

While; cancer, chronic renal disease, and coronary heart disease, represented lower frequencies $(1.1 \%, 2.6 \%$, and 3.7\%; respectively). Moreover, these finding matched El-Zorkanyet al. ${ }^{\mathbf{1 3}}$ study as they found that cancer, chronic renal disease, and coronary heart disease, represented lower frequencies $(0.3 \%, 1.3 \%$, and $3.2 \%$; respectively).

In our study RA patients with comorbid conditions were significantly older and had longer duration ofDMARDs treatment than those with-out comorbid diseases. Rural area residency and Illiteracy were significantly associated with comorbidity among RA patients. As regarding treatment, patients with prescribed NSAIDs, or prednisolone showed significantly higher prevalent comorbidities $(\mathrm{p}<0.0001)$. And when we comparing RA severity index, we found highly statistically significant differences between RA patients with comorbidity than RA patients without comorbidities

Our study was in agreement with the study done by Osiri\&Sattayasomboon ${ }^{4}$ they found that RA patients with comorbid conditions were significantly older and had longer duration of DMARDs treatment than those without comorbidity.

Moreover, Espiño-Lorenzoet al. $^{20}$ observed that age is the main predictive factor of comorbidity in these RA patients. They identified four factors associated with comorbidity in the univariate analysis, two related to age and the rest related to the severity of RA, however, age was the only predictive factor for both comorbidity and multimorbidity in the multivariate analyses. Because many health problems are known to increase with age, this demographic trend may lead to an increase in the absolute number of chronic conditions in RA patients. For this reason, age always appears as the strongest predictor of comorbidity in addition to pre-existing comorbidity in RA patients.

In study done by El-Zorkanyet al. ${ }^{\mathbf{1 3}}$, they observed that the degree of RA disease activity found among Egyptian patients (highest ever among different COMORApopulation cohort) might reflect that the reason for patients visiting the rheumatologist is a flare of disease activity. In some countries, patients are evaluated routinely even when their 
RA is under good control. So, uncontrolled RA disease contributes to the increased risk of comorbidity in RA patients.

In addition, Navarro-Cano et al. ${ }^{\mathbf{2 1}}$, concluded that both comorbidity and RA severity scales displayed strong bivariate associations with the probability of survival, and these associations were statistically significant.

\section{Conclusion:-}

This is the first time to apply the severity index for RA among Egyptian RA patients and we found that the Egyptian patients have relatively high scores of severity but may not reflect the actual severity nature of the disease as they have the higher score in the clinical activity subscale and this continuously active disease may be due to socioeconomic problems in our country. We found also high percent of comorbid conditions associated with the disease with significant relationship with the severity index.

Limitation of our study is the retrospective nature, since some data may be overlooked; additionally, data regarding the impact of comorbidities on disease activity and quality of health were not available. New researches should focus on the complex interdependencies between RA severity and comorbidity. The RARBIS may have great utility for researchers using medical record.

\section{References:-}

1. Gabriel S, Michaud K. Epidemiological studies in incidence, prevalence, mortality, and co-morbidity of the rheumatic diseases. Arthritis Res Ther. 2009; 11:229.

2. Osiri M, Maetzel A. The economic burden of rheumatoid arthritis: Asia/Thailand perspective. In: Preedy VR, Watson RR, editors. Handbook of disease burdens and quality of life measures. New York: Springer Science + Business Media; 2010. p. 1733-50.

3. Kvien TK. Epidemiology and burden of illness of rheumatoid arthritis. Pharmaco-economics 2004; 22:1-12.

4. Osiri $\mathrm{M}^{1}$ and Sattayasomboon Y.: Prevalence and out-patient medical costs of comorbid conditions in patients with rheumatoid arthritis. Joint Bone Spine.2013 Dec; 80(6):608-612.

5. Gabriel SE.: Why do people with rheumatoid arthritis still die prematurely? Ann Rheum Dis. 2008; 67(3):iii3034.

6. Furst D., Chang H., Greenberg J., et al.: Prevalence of low hemoglobin levels andassociations with other disease parameters in rheumatoid arthritis patients:evidence from the CORRONA registry. ClinExpRheumatol 2009; 27:560-6.

7. Ikwer M., Bergstrom U., Nilsson J., et al.: Early menopause is an independent predictor of rheumatoid arthritis. Ann Rheum Dis. 2012;71(3):378-81.

8. Cabral D., Katz J., Weinblatt M., et al.:Development and assessment of indicators of rheumatoidarthritis severity: results of a Delphi panel. Arthritis Rheum 2005; 53:61-66.

9. Siebert S., Lyall D., Mackay D., et al.: Characteristics of rheumatoid arthritis and its association with major comorbid conditions: cross-sectional study of UKBiobankparticipants.RMD Open.2016; 2(1):e000267. doi: 10.1136/rmdopen-2016-000267.

10. Dougados M.,Soubrier M., Antunez A. and Balintet P, et al.: Prevalence of comorbidities in rheumatoid arthritis and evaluation of their monitoring: results of an international, cross-sectional study (COMORA) Ann Rheum Dis 2014;73:62-68.

11. Ikuyama S, Imamura-Takase E, Tokunaga S, Oribe M, Nishimura J. Sixty percent of patients with rheumatoid arthritis in Japan have used dietary supplements or health foods. Mod Rheumatol. 2009;19(3):253-9.

12. Sineglazova AV, Kalev OF, Trushin IV, Rostovtsev MV. Special features of coronary artery involvement in women with rheumatoid arthritis. Kardiologiia. 2012; 52(8):44-7.

13. El-Zorkany B\&Mokbel A and Gamal S., et al: Comparison of comorbidities of the Egyptian rheumatoid arthritis patients to the global cohort of the COMORA study:a post-hoc analysis.ClinRheumatol (2016) 35:1153-1159

14. Briggs AM, March L, Lassere M, et al. Baseline comorbidities in a population-based cohort of rheumatoid arthritis patients receiving biological therapy: data from the Australian Rheumatology Association database. Int J Rheumatol2009; 2009:861481.

15. Al-Bishri J, Attar S, Bassuni N, Al-Nofaiey Y, et al: Comorbidity Profile Among Patients with Rheumatoid Arthritis and the Impact on Prescriptions TrendClinical Medicine Insights: Arthritis and Musculoskeletal Disorders 2013;6: 11-18. 
16. Sato M., Schneeweiss S., Scranton R., et al.: The validity of a rheumatoid arthritis medical records-based index of severity compared with the DAS28.Arthritis Research \& Therapy; 2006, 8:R57 (doi:10.1186/ar1921)

17. El Zorkany B, Alwahshi HA, Hammoudeh M et al (2013): Suboptimal management of rheumatoid arthritis in the Middle East and Africa: could the EULAR recommendations be the start of a solution? ClinRheumatol; 32(2):151-159.

18. Van Hoogmoed D., Fransen J., Bleijenberg G., et al.: Physical and psychosocial correlates of severe fatigue in rheumatoid arthritis. Rheumatology (Oxford) 2010;49:1294-302. doi:10.1093/rheumatology/keq043.

19. Matcham F., Rayner L., Steer S., et al.: The prevalence of depression in rheumatoid arthritis: a systematic review and meta-analysis. Rheumatology (Oxford). 2013;52:2136-48.

20. Espiño-Lorenzo P., Manrique-Arija S, Ureña I, et al.: Baseline comorbidities in patients with rheumatoid arthritis who have been prescribed biological therapy: a case control study. ReumatolClin. 2013 JanFeb;9(1):18-23.

21. Navarro-Cano G., delRincón I., Pogosian S., et al.: Association of Mortality With Disease Severity in Rheumatoid Arthritis, Independent of Comorbidity. ARTHRITIS \& RHEUMATISM; 2003, 48( 9): 2425-2433

\section{Abbreviations:-}

RA: Rheumatoid Arthritis

RARBIS: Rheumatoid arthritis medical records-based index of severity index

NSAID:Non-steroidal anti-inflammatory drug

ESR: Erythrocyte sedimentation rate

CRP: C-reactive protein

RF: Rheumatoid factor

DMARDS :Disease-modifying Anti-rheumatic Drugs 